\title{
The role of libraries and transformations in scientific communication
}

\author{
Giovanni Solimine
}

Published online: 28 January 2014

(C) Centro P.RI.ST.EM, Università Commerciale Luigi Bocconi 2014

\begin{abstract}
Library institutes that have traditionally acted in support of researchers, placing sources and instruments for research at their disposal, but the transformations underway in scientific communication gave meant that the roles of those who mediate between documents and their contents and users-such as the librarian-have been blurred until they are practically unrecognisable. There is a concrete risk that this could end in a kind of 'total dismediation'. Today, alongside their traditional roles, scientific libraries and institutions also have new missions, such as the services of the digital library or the development of open access models of dissemination, as well as training users in the rational use of new instruments.
\end{abstract}

Keywords Information overload · Scholarly communication · University libraries · Information literacy

The modes of scientific communication are undergoing profound transformations, due in part, but not solely, to the effect of technological evolution. It is evident that a variety of factors-the migration of an increasing number of publications from print to digital, the practice of online sharing of research results in progress, the need for rapid and exhaustive circulation of these results, as well as the economic crisis, which, as far as Italy is concerned, has been accompanied by an attack on the system of public education and research, translating into years and years of cuts in funding to universities-have radically changed the way scholars behave.

G. Solimine $(\bowtie)$

Dipartimento di Scienze documentarie, linguistico-filologiche e geografiche, Viale Regina Elena 295, 00161 Rome, Italy

e-mail: giovanni.solimine@uniroma1.it
Given the complexity of this panorama, it may be helpful to reflect on the role played by library institutes that have traditionally acted in support of researchers, placing sources and instruments for research at their disposal.

Contemporary society has shown its capacity for producing and accumulating an enormous quantity of knowledge, sometimes leading to such a overabundance that it is possible to characterise it as an 'information overload' [12]. The Internet promises to give everything to everyone with a minimum of effort, and tends to generate an intoxicating sense of informational omnipotence. At least apparently it is easy to have a direct, unmediated contact between supply and demand of information and documents, bypassing or totally neglecting the functions of analysing the request, selecting documents, validating contents, directing and orienting the user, guiding access, all of which are proper to the work of mediation historically performed by libraries. There is a concrete risk that this could end in a kind of 'total dismediation', without considering that the hazards that this mode of working could lead to.

Day-to-day experience teaches us that we need only insert a word or phrase into a search engine to come up with a huge number of listings, even if they are not always pertinent. The phenomenon of informational overabundance can be seen both on the side of production and that of consumption. In the digital age documents appear to acquire a great visibility and accessibility, and that lead to the accumulation of a remarkable quantity of material, perhaps even beyond our needs and without our being able to make adequate use of it. We are immersed in a complex system of documentation that owes its rate of growth not least to the ease with which technology today makes it possible to publish, that is, to make what is produced public and accessibly. Developments in electronic publishing and the 
new frontiers in self-publishing have only made this situation more evident. It goes without saying that while any expansion of the limits of knowledge is to be considered positive, the present situation is not without its dangers, and not only because the excess of quantity can occur at the expense of quality. What we must be even more concerned about is the damage that can derive from the banal ease with which documents circulate, and therefore of the risk that is minimised by careful selection, putting into context, validation and filtering that occur at the different stages of informational and documentational mediation. In the age of 'do-it-yourself' and global communication, the function of some of those who mediate between documents and their contents and users-such as the publisher, the bookseller, the librarian, as well as, in a certain sense, figures such as teachers-have been blurred until they are practically unrecognisable. This also occurs when the roles are performed by professionals: think, for example, of the way in which the university user accesses the resources of electronic publishing. Due to the simple fact that there is no reason to physically go to the library, and that these resources can be accessed from the user's office or laboratory, or the fact that search engines send us directly to the site of a journal or publisher, the work performed by the libraries, and in a certain sense also the financial resources that the universities have invested to make these resources usable, become totally invisible-especially to the eyes of those who work in the hard sciences.

There is also a dangerous tendency towards simplification: the majority of those who use search engines do so in quite elementary ways, based on a few keywords, and tend not to go beyond the first results, without having evaluated their pertinence, relevance and reliability, and thus without having an appropriate critical examination and awareness of the contents. What is worrisome is that this self-limiting of the possibilities of research is spreading not only among 'normal' surfers of the web, but also among students, and worse still, among researchers, as several studies have shown [8].

To this must be added transformations that we might almost define as being of an anthropological nature, regarding the sphere of personal thinking and attitudes: the reception of contents recorded on digital supports is different from reception tied to canonical forms of reading, studying and learning. A multilinear reading, often done contemporaneously with other activities (multitasking), and performed while constantly jumping from one medium to another, from one channel to another, generates a cognitive overload. ${ }^{1}$ Different cognitive areas are being solicited with respect to the past, and new habits and skills are being developed, while others are being forgotten or

\footnotetext{
${ }^{1}$ See the interesting remarks in [Mauri 2012] and [3].
}

completely lost. ${ }^{2}$ In the analogue universe, the linearity of the written text required time for concentration and reflection, while in the digital world the user learns to 'read without reading', scanning the text almost unconsciously, alternating phases of attention with others of complete inattention, sometimes submitting passively to and without participation in the routes of hypertext links. The capacity to read and understand text that discusses a topic point-bypoint becomes more a question of instinct than of cognition, but comprehension is different when reality is virtual, and skills are assimilated by trial-and-error more than by a process where theory precedes action.

Another thing that is being erased is the canonical distinction between the various forms of social organisation of knowledge that the sociologist Guido Martinotti defined so very effectively many years ago [6], when he spoke of 'organised knowledge', organising knowledge' and 'diffuse knowledge'.

By the expression 'organised, or cultivated, knowledge' Martinotti intended the kind of knowledge that was connected with scientific institutions, systematically organised, produced and transmitted by scholars and experts, naturally destined to be conserved and re-formulated by means of a constant process of progressive growth of knowledge. For our part, we can add to this definition an internal distinction between hard sciences and humanities and social sciences that involve a different method of study as well as a different relationship with documentary sources. In the case of the hard sciences, progress in research proceeds by surpassing previous research, while in the humanities research goes forward thanks to a progressive accumulation and deepening of what has been done before. We shall return in a moment to this kind of knowledge, which is of particular interest to us here.

Another form of knowledge is what Martinotti defined as 'organising knowledge' (or 'bureaucratic' in Max Weber's sense of the term) and which comprises the knowledge that is accumulated within the large, formal organisations, both public or private, that characterise the age we are living in. This kind of knowledge, which is commonly described as 'know how', is made up of 'complex normative documents, extensive written reports on the behaviour of organisations, detailed and exhaustive data regarding the characteristics and dynamics of all these institutions, the men who are part of them and the milieu in which they operate' ([6]: 146, our trans.). Because this knowledge is constantly evolving and is closed tied to individual and collective experience, with a function that is eminently practical and applicative, it is not necessarily tied to written form. However, in this case as well the Internet has become an important depository for its

\footnotetext{
${ }^{2}$ In addition to [Mauri 2012] and [3], see [2, 9, 11, 13].
} 
accumulation and use; in particular I refer to those circuits reserved for professional communities or well-defined interest groups.

The third and final category of knowledge that Martinotti described is 'diffuse knowledge', whose production, accumulation and dissemination are shared by a plurality of users. On the basis of this kind of knowledge are formed the collective consciousness related to events of everyday life and the opinions, uses and habits of millions of people. First newspapers and then television were previously the principal instruments of transmission - the basic school, we might say-for moulding this amalgam of social tissue. Here again the Internet, especially given the capillary diffusion of portable devices, is a candidate for becoming the most important shaper of collective consciousness of our age.

Until a short time ago we could have related these three different forms of knowledge unequivocally to as many different kinds of publishing venues (essays and academic publications in the first case; professional journals and 'grey literature' in the second; newspapers and popular periodicals in the third), or to three different kinds of institutions appointed to the conservation and diffusion of the cultural products that were vehicles for this different forms of knowledge (respectively, research libraries, centres for documentation, and public libraries). The means of mass communication and Internet have unhinged this welldelineated scheme of reference, and in some cases, have also blurred the distinctions that separated each of these three worlds of knowledge from the others.

The lesser degree of formality of the channels of communications and of these functional distinctions have made themselves felt in various ways. There are, for examples, instruments such as discussion groups, and in some ways even blogs, that operate in each of the three areas and which sometimes tend to go beyond their original primary aims, and which serve more than one purpose contemporaneously. Further, the integration of languages and forms and the possibility of combining text and images (including images that are animated and three-dimensional) is moving in this direction. Other examples could be cited.

With regard to 'scholarly communication', that is, with techno-scientific communication that utilises a specialised language and is aimed at a restricted community of researchers, it has become easier to flank this with a more accessible kind of communication which addresses a broader collective but without renouncing quality and rigour. For an audience that is still more vast and diversified there are several venues, such as the channels of satellite television specialising in popular sciences and the communities that form around social networks and other instruments that are typical of Web 2.0, which have further diversified and mixed the traditional means of communication through the contents travel.
In any case, precisely to increase the flow of communication and the presumed ease with which it can be accessed, skills of critical thinking and reading are required in order to fully enjoy the potentials of this huge quantity of contents. To this end it is necessary to 'acquire models, motivation and ability to direct, even independently, a process of continuous updating and development of knowledge, such as to favour the possibility of self-control and design of interventions with respect to the individual context of life and work' ([4]: 14; our trans.). For all of these reasons, I believe that it is fundamental to seriously address the question of 'information literacy', that is, the capacity to recover information by means of effective strategies for researching, selecting and evaluating the information found, organising and reformulating the contents, and knowing how to present and communicate the results of one's work. ${ }^{3}$

It is precisely in this specific field of activity that we can identify a broadening of the concept of the role of mediation which was mentioned earlier with regard to libraries. The formative function of the library is valid for all the types of institutions that are usually labelled in this way, but first and foremost those that are found within schools and universities. We can say that the effectiveness of a school or university library is measured by the contribution that it is able to make to its institution in achieving its objectives. In fact, a library is not only a service in support of activities of teaching and research, with a role that is merely ancillary, but also one of the components of the educational process that is performed in these institutions, a laboratory in which we learn to learn, where we work with the sources, we use contemporaneously primary and secondary instruments, specialised instruments and more general auxiliary instruments.

Arriving to specifics regarding Italian situation, we must unfortunately admit that we do not have at our disposal the up-to-date information that can precisely and reliably describe the healthiness of our own university libraries 4

\footnotetext{
${ }^{3}$ See the guidelines assembled by the American Library Association (ALA): http://www.ala.org/acrl/issues/infolit (accessed 9 December 2013). The definitions and summaries of the ALA have been adopted almost verbatim in the document compiled by the International Federation of Library Associations and Institutions (IFLA) in 2006, "Guidelines on information literacy for lifelong learning": http:// archive.ifla.org/VII/s42/pub/IL-Guidelines2006.pdf (accessed 9 December 2013).

${ }^{4}$ The results of the survey that the Gruppo interuniversitario di monitoraggio begun some time ago regarding the data up to 31 December 2010 have not yet been made public. Those of the previous survey (based on data of 2002 and 2006) are by now rather outdated; in any case, they tell us that in 2006 only $1.16 \%$ of students had attended training courses in the use of resources organised by libraries - only three universities, Sant'Anna in Pisa, University of Bolzano and University of Camerino, showed a percentage greater than $10 \%$-and that only twelve universities had allotted more than $100 \mathrm{~h}$ of teaching for users. See: http://www.gimsba.it/node/ 4(accessed 09 December 2013).
} 
from this point of view, nor their involvement in the training of users. Even though the situation is changing rapidly, ${ }^{5}$ in 2011 only a quarter of our universities had begun formal projects in this area and carried them out systematically and with continuity [10].

A recent document, compiled by the Italian National Commission for Universities and Research of the Italian Library Association (Associazione Italiana Biblioteche, or AIB), attempts to redefine the role of university and research libraries as "basic infrastructures for the creation, dissemination and conservation of scientific research and for the construction of services to support and enhance educational activity'. ${ }^{6}$ This is a high-profile document that expresses an integral and advanced vision of the functions that library services might and should perform within the university, and which is probably limited only by turning out to be rather far from the current setup, which is characterised by a certain marginalisation with respect to the dynamics of academic life and by a strongly inadequacy of human, financial and instrumental resources. For the libraries working in the university and research sector, the AIB has identified several areas for interventions aimed at creating a strategy for the development of knowledge and information that are rational and economical sustainable. Such lines of activity can be summarised as follows:

- a renovated structural and administrative organisation;

- the expansion of the current functions of the libraries;

- the assumption of roles of coordination and support in the following areas of development:

(a) sharing of knowledge;

(b) diffusion of open access;

(c) evaluation of research;

(d) user education and training.

- recognition of new roles and skills and the identification of educational programs for professional librarians and information mediation.

At a juncture that appears oriented to the commercial exploitation of information and to the privatisation of sources and channels of transmission of knowledge, and which is characterised by the consolidation of new models of publishing and economic logic of vertical integration and concentration in restricted oligopolies of knowledge, university and research libraries reaffirm their role as a public service open to the use of multiple communities of users. But the transformation under way are profound and

\footnotetext{
5 In the professional literature in Italy as well there has been a growing interest in these topics. To cite only the most comprehensive work, see [1].

${ }^{6}$ See: http://www.aib.it/struttura/commissioni-e-gruppi/2013/36257rilanciare-le-biblioteche-universitarie-e-di-ricerca-italiane/ (accessed 9 December 2013).
}

new subjects-enterprises such as Google and Amazon come to mind-are attempting to take over the functions of production and mediation in the chain of scientific communication and publishing. Hence, alongside their traditional roles, scientific libraries and institutions also have new missions, such as the services of the digital library or the development of open access models of dissemination. There are therefore remarkable opportunities for libraries which are oriented towards production, treatment and sharing of free contents and knowledge, unconditioned by the requirements of a commercial nature.

As formulated in the document we have just summarised, but also advanced on other fronts as well, the hope is that libraries of universities and research centres will become increasingly involved in the creation of open access projects: a movement born in part as a reaction to the rising costs of scientific publication that have become unsustainable (in the space of two decades, the increase in price of periodicals has been equal to six or seven times the rate of inflation), but which is primarily inspired by the institutional aims of the libraries that offer extensive and democratic access to knowledge. To be precise, I would like to remark on the attempt made in recent months to introduce an innovation that is of great importance for Italy.

Article 4 of the legislation ${ }^{7}$ proposed by the government headed by Prime Minister Enrico Letta called for publications that document the results of research which is at least $50 \%$ funded with public money to be made available within 6 months in institutional archives that are open access. During the process of enacting the law, several amendments were introduced which effectively hollowed the proposal out. The result is legislative decree no. 112/2013: the limitation of the obligation of publication in open access to only periodicals and the extension of the period of restricted access from 6 to 18 months for the scientifico-techological fields and to 24 months for humanities and social sciences severely reduces the significance of the measure. As many had feared, the publishing lobby prevailed.

Coming back to the issues of 'information literacy' and user training that were mentioned earlier, in its document the AIB remarks that the capacities for analysis and interpretation are not created spontaneously among users but are the result of specific courses that are very closed related to the categories of disciplinary documentation and to the distinct practices of the research community. In the 'recommendations' that accompany the document we read

\footnotetext{
7 Legislative decree no. 91 of 8 August 2013, "Disposizioni urgenti per la tutela, la valorizzazione e il rilancio dei beni e delle attività culturali e del turismo", published in the Gazzetta Ufficiale (Serie Generale 186, 9 agosto 2013).
} 
that it is indispensable that universities and their libraries provide programs of education and training for users. They propose that libraries, in collaboration with the community of teachers, integrate the contents of curricular programs with hours of lessons, recognised by boards of accreditation, dedicated to the use of the physical library, the digital library, and the advanced tools for searching for and disseminating of information.

In conclusion, we can say that it is not possible to redefine the role of university libraries and envision a more incisive position for them without engaging in a broader reflection on the transformations taking place in scientific communication and in learning.

Translated from the Italian by Kim Williams.

\section{References}

1. Ballestra, L.: Information literacy in biblioteca. Editrice Bibliografica, Milan (2011)

2. Casati, R.: Contro il colonialismo digitale. Laterza, Rome-Bari (2013)

3. Ferri, P.: La scuola digitale. Come le nuove tecnologie cambiano la formazione. Bruno Mondadori, Milan (2008)

4. Ferri, P., Marinelli, A.: New media literacy e processi di apprendimento. In: Jenkins, H. (ed.) Culture partecipative e competenze digitali. Media education per il XXI secolo. Guerini e associati, Milan (2010)

5. Levy, R.: You have to understand words...but not read them: young children becoming readers in a digital age. J. Res. Read. 32(1), 75-91 (2009)

6. Martinotti, G.: Informazione e sapere. Anabasi, Milan (1992)

7. Mauri, C.: Leggere in digitale. AIB, Rome (2008)
8. Metitieri, F.: Il grande inganno del Web 2.0. Laterza, Rome-Bari (2009)

9. Mussinelli, C.: Cultura e intrattenimento nel mondo digitale. Una ricerca dell'Osservatorio sui contenuti digitali dell'AIE. Libri e riviste d'Italia 5(1-5), 49-65 (2009)

10. Renditiso, A.: L'information literacy nelle biblioteche universitarie italiane: i risultati di un'indagine comparati con le modalità di comunicazione del servizio sul Web. Bollettino AIB 51(3), 213-226 (2011)

11. Roncaglia, G.: Leggere in formato digitale. In: Gamba, C., Trapletti, M.L. (eds.) Le teche della lettura, pp. 82-90. Editrice Bibliografica, Milan (2006)

12. Salarelli, A.: Le patologie da eccesso di informazione: l' "information overload". In: Salarelli, A. (ed.) Bit-à-brac. Informazione e biblioteche nell'era digitale, pp. 43-63. Diabasis, Reggio Emilia (2004)

13. Wolf, M.: Proust and the Squid: the story and science of the reading brain. Harper Collins, New York (2007)

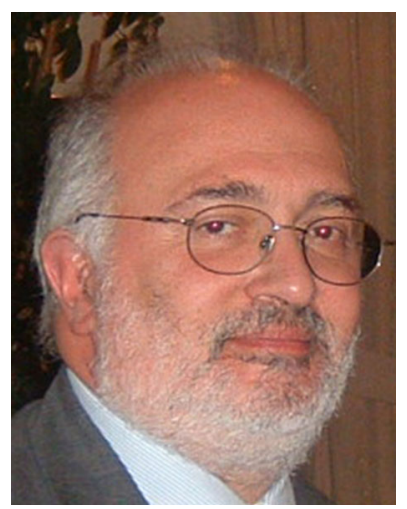

Giovanni Solimine teaches Library Management at the Sapienza Università di Roma. He is director of the Postgraduate School of Archive and Library Science, and president of the University Library System. 